\title{
MARKETING ONLINE USING CHANGE REQUEST MANAGEMENT
}

\author{
D. SAS ${ }^{1}$, H. SILAGHI ${ }^{1}$, A. MESAROS ${ }^{1}$, M. NEAGU ${ }^{2}$, D. SPOIALĂ ${ }^{1}$, A.M. SILAGHI ${ }^{1}$ \\ ${ }^{1}$ Control Systems Engineering Department, University of Oradea, Str. Universităţii nr. 1, Oradea, Romania \\ ${ }^{2}$ Computer Science Department, Technical University Cluj-Napoca, Str Memorandumului nr.28 Cluj-Napoca, Romania \\ E-mail: dsas@uoradea.ro
}

\begin{abstract}
In this paper is presented the change request management approach of a web-based application which represents an online marketplace for local producers. Nowadays, for all type of businesses, working both offline and online is a must. In digitalization era, the fast development of a compact online marketplace platform involves both a wellestablished project plan and change management control system.
\end{abstract}

Keywords: project management, software development, project plan, change request, web-based application, online marketplace

\section{INTRODUCTIOBN}

Nowadays, the necessity of an online marketplace has significantly increased. Digitalizing the businesses is not a luxe or a futuristic approach, is a way of keeping the business alive. Starting from important international hypermarkets to small local business, selling the products both offline and online is a way of surviving.

Both for customers and sellers, the existence of online market is essential. Sellers, in this case local producers of fresh groceries and animal products, want to find buyers interested in healthy goods meanwhile customers want to stay in shape and healthy, and for this, a balanced diet is recommended. Like Figure 1 suggests, these days, the interaction between user and online marketplace significantly increased.

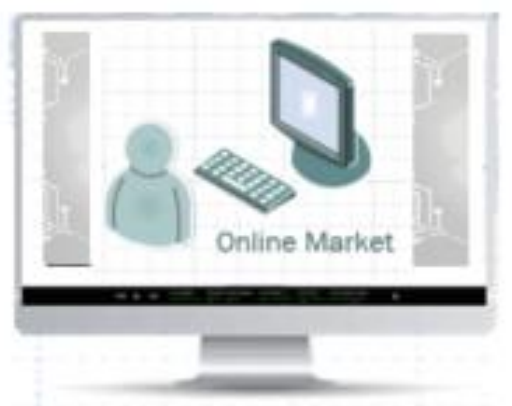

Figure 1. Online market

The online marketplace presented in this article represents a necessity for local producers to sell their products, nowadays when local marketplaces are either closed, or there is a limited number of people that have access one time. Another important fact to mention is that people are avoiding crowded places, so ordering online healthy fresh grocery, milk and meat is a necessity.

\section{PROJECT PLANIFICATION}

In Project Management terms, a project represents a set of related activities that use human, time and financial resources. These activities are performed to provide a purpose and several objectives. As a business concept, a project should determine a change in business [1-3].

Either for a small local business or for an international multinational business, the change should increase productivity, profitability or should lead to visible business improvements.

A traditional development project follows a linear approach. Using the Waterfall methodology, for the classic implementation of a project, the following steps represented in Figure 2 must be performed [4-5]:

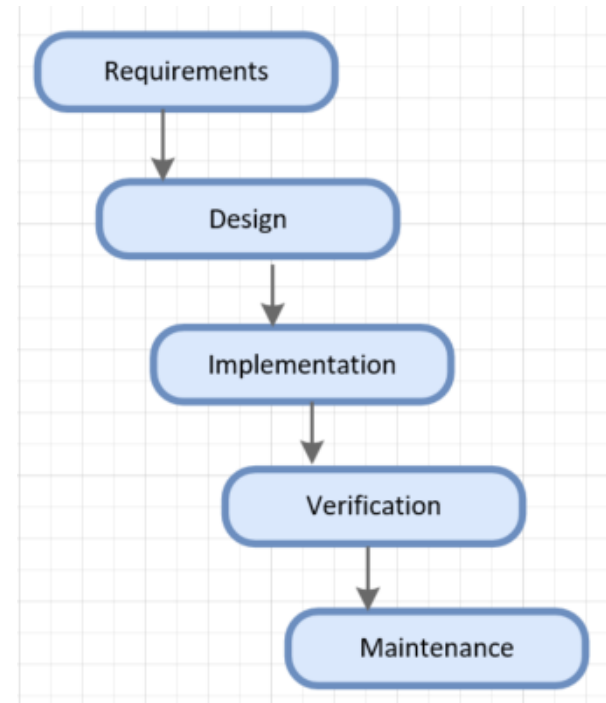

Figure 2. Project steps

In this part of the paper is presented a high-level project planification for a web-based application which represents an online marketplace for local producers. The scope of the marketplace is to help the locals to sell fresh groceries, milk products and meat.

In Figure 3 is represented a classical software development team including project manager, business analysts, development team, testing team and IT infrastructure representatives [1-5]. 


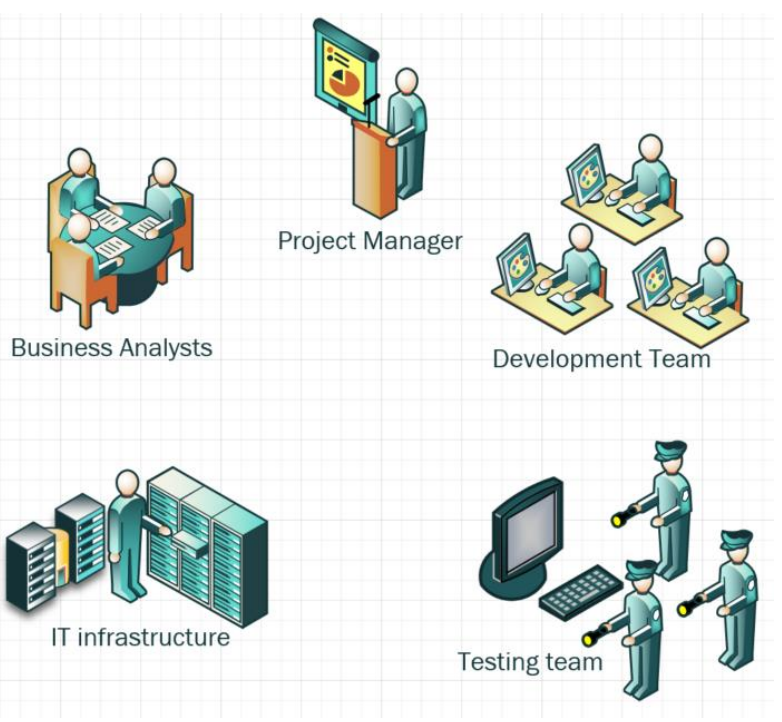

Figure 3. Project team
Like it is mentioned in the literature, the initial step in developing a software application is to create the project plan [1-3].

In Figure 4 is represented a high-level scheme for an online application, including all the necessary steps that should be performed to have a fully functional up and running application. The presented project plan is divided in seven individual steps, each step contains the following information [1-3]:

- $\quad$ headline - name of the activity performed in that step.

- $\quad$ start date.

- finish date.

- cost estimated in euro.

- time estimated in man days.

- the responsible for deliverable.

- the deliverable.

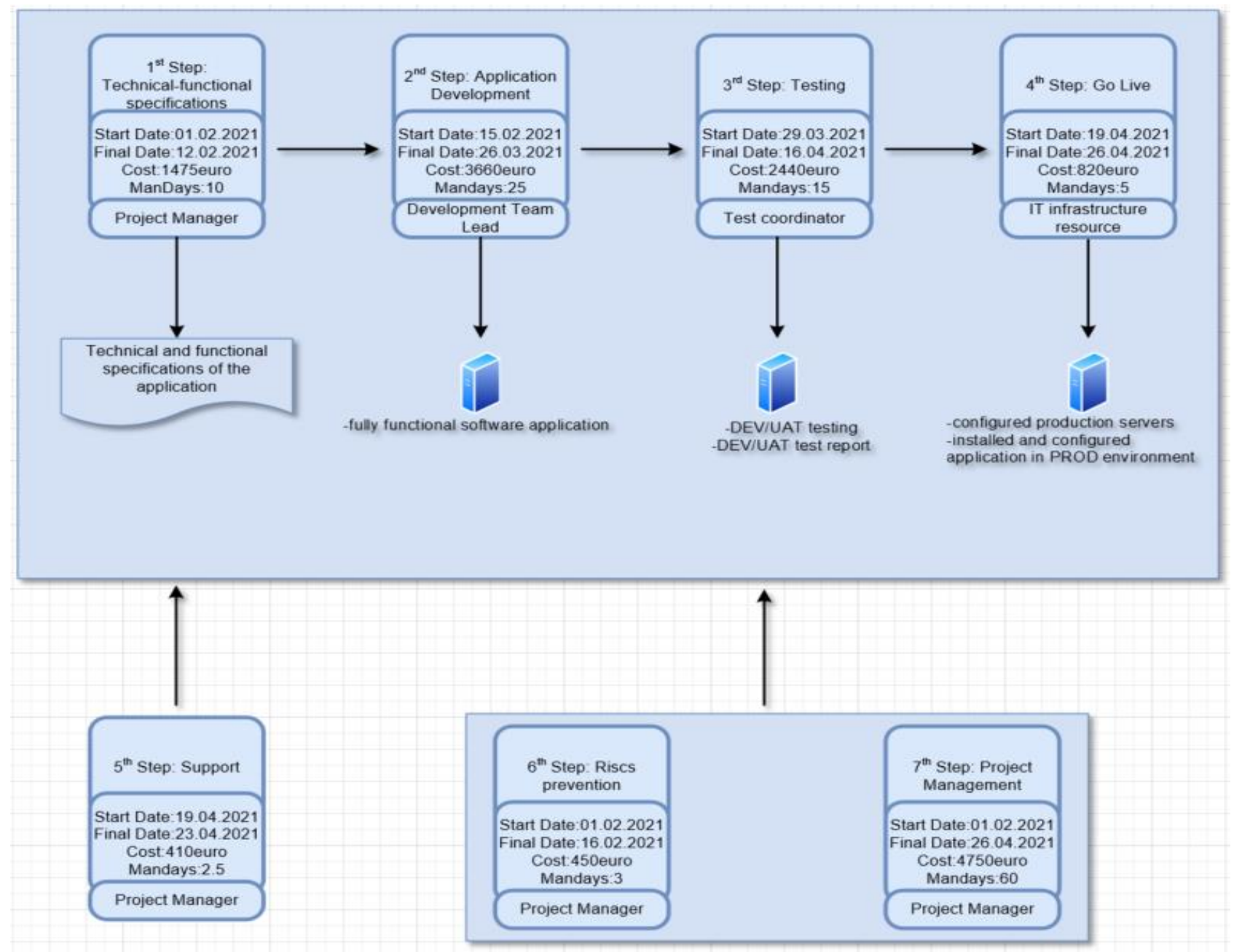

Figure 4. Project planification for a web-based application

For accomplishing each step, there is at least one project team member who performs a specific task in a specific time period with a specific cost. Each man day is estimated in eight working hours. Each task is estimated in hours. 
There are tasks that might be performed in several days, divided in time period, at least 0.5 hour/day. For each task there is one or more project team members allocated in a specific time period.

Deliverables are divided into two categories such as project deliverables and management deliverables. Each deliverable has a specific responsible as shown in following tables (Table 1, Table 2):

Table 1. Major project deliverable and its responsible

\begin{tabular}{|l|l|}
\hline \multicolumn{1}{|c|}{ Deliverable } & \multicolumn{1}{|c|}{ Responsible } \\
\hline $\begin{array}{l}\text { Technical and functional } \\
\text { specifications of the application - } \\
\text { pdf version }\end{array}$ & Project Manager \\
\hline $\begin{array}{l}\text { Online marketplace - fully } \\
\text { developed web application }\end{array}$ & $\begin{array}{l}\text { Development } \\
\text { Team Lead }\end{array}$ \\
\hline $\begin{array}{l}\text { Online marketplace - fully tested } \\
\text { web application }\end{array}$ & Test coordinator \\
\hline $\begin{array}{l}\text { Configuration of production } \\
\text { servers }\end{array}$ & $\begin{array}{l}\text { IT infrastructure } \\
\text { resource }\end{array}$ \\
\hline $\begin{array}{l}\text { Migrated application in production } \\
\text { environment }\end{array}$ & $\begin{array}{l}\text { IT infrastructure } \\
\text { resource }\end{array}$ \\
\hline Training sessions & Project Manager \\
\hline User guide & Project Manager \\
\hline
\end{tabular}

Table 2. Major management deliverable and its responsible

\begin{tabular}{|l|l|}
\hline \multicolumn{1}{|c|}{ Deliverable } & Responsible \\
\hline $\begin{array}{l}\text { Technical and functional } \\
\text { specifications acceptance criteria } \\
\text { report }\end{array}$ & Project Manager \\
\hline Development acceptance report & Project Manager \\
\hline User acceptance test report & Project Manager \\
\hline Go Live report & Project Manager \\
\hline Project monitorization report & Project Manager \\
\hline
\end{tabular}

During the project, there are some communication rules that should be fulfilled between implementation team members, project manager and client/sponsor or shareholders of the project.

In the presented case, the communication between Client and Project manager is bidirectional and fulfilled using emails and phone calls, having an agreed response time. The communication between project manager and project implementation team is also bidirectional and having an agreed response time, but in this case is fulfilled using face to face communication, internal chats and emails and phone calls.

The reporting plan between project manager and Client is fulfilled through project status report meanwhile the reporting between implementation team and project manager is fulfilled through activity report.

In the Figures 5 and 6 are presented the communication plan and the reporting plan between project client, project manager and the implementation team:

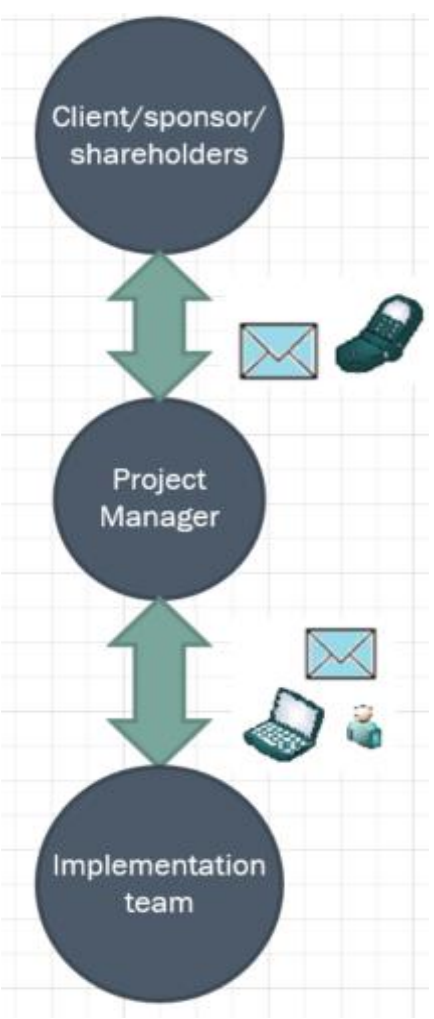

Figure 5. Communication rules

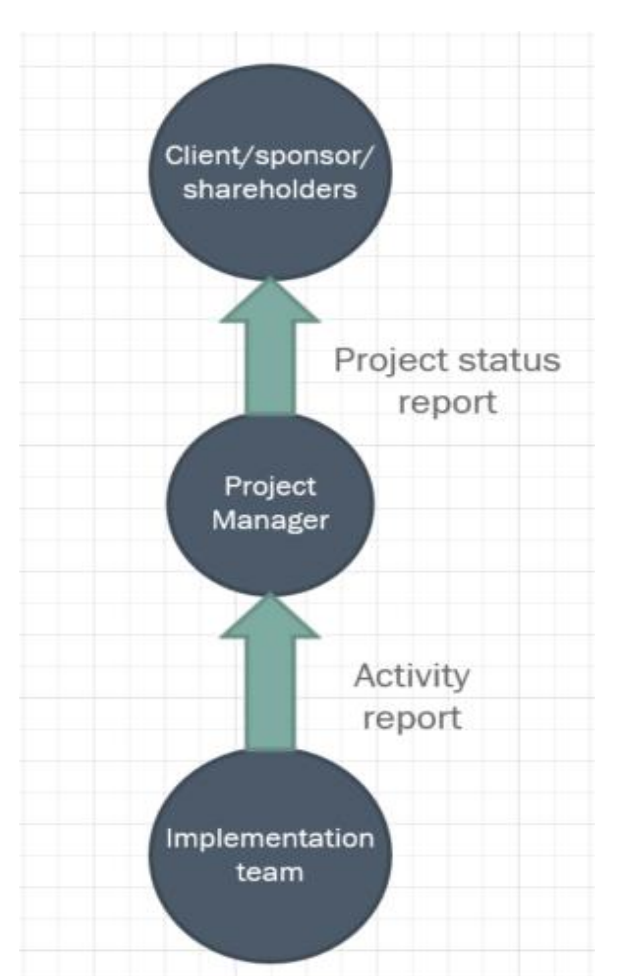

Figure 6. Reporting rules

\section{CHANGE REQUEST MANAGEMENT}

Nowadays, fast development of a compact stable and robust online marketplace platform involves both a wellestablished project plan and change management control system. 
In order to avoid delays and additional implementation costs, the change request management approach should be well analyzed by project manager and business analysts [68].

Using the classic methodology of project management, change requests may be initiated either by Project Manager or by the Client.

Therefore, change requests are sent to the Project Manager by email, and a change request analysis meeting will be organized according to the project rules. Any change request must be [9-12]:
- justified

- accompanied by impact analysis

- $\quad$ assumed

The impact analysis is done by the business analyst, project client and project manager. The analysis takes place through direct meetings, emails and by phone. Filling the change request document is made by the applicant [1-3, 9-12].

In Figure 7 is represented the flow for proposed change request management approach [1-3, 9-12].

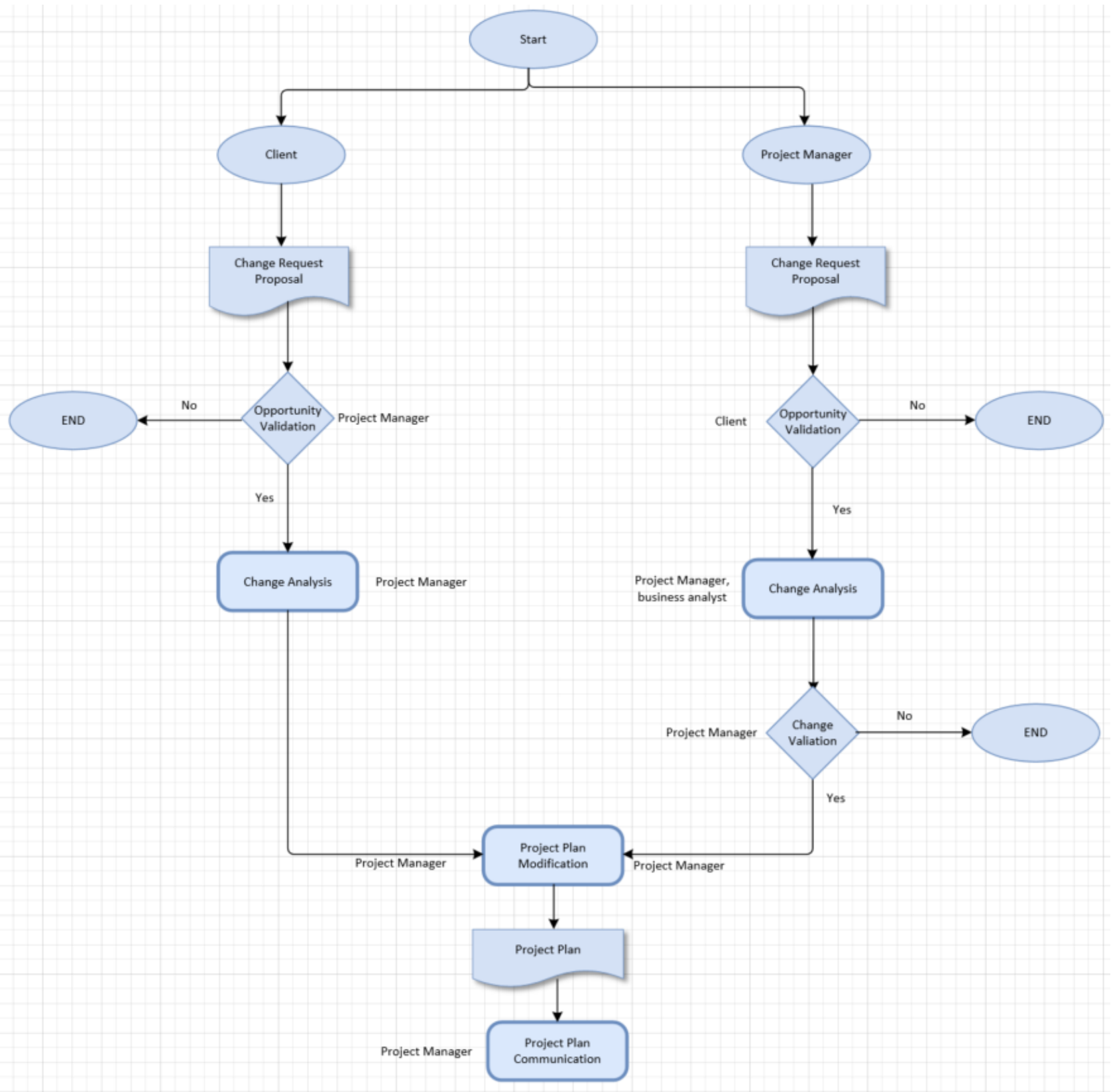

Figure 7. Change request management 


\section{CONCLUSIONS}

In this paper was presented the change request management approach for a web-based software application which represents an online marketplace for local producers.

The web-based software application presented in this article represents a necessity for local producers to sell their products, nowadays, when local marketplaces are either closed, or the access is limited. Since people are avoiding crowded places, but still want a healthy living, ordering online fresh grocery, milk and meat is a necessity.

Therefore, developing fast a solid platform for an online marketplace involves a well-established project plan and change management.

For a suggestive and clear representations, all figures and diagrams presented in this paper were obtained using Microsoft Visio and Paint.

\section{REFERENCES}

[1] Project Management Institute, A guide to the Project Management Body of Knowledge (PMBOK guide), 2018.

[2] J Heagney Fundamentals of Project Management, New York: AMACOM, 2011.

[3] Griffiths M., PMI-ACP Exam Prep: Rapid Learning to Pass the PMI Agile Certified Practitioner, Editura Rmc Pubns Inc, 2015.

[4] Gladwell R., PMP Exam Prep: How to Pass on Your First Attempt, ISBN 979-8644739363, pg 283, 2020.

[5] Bagnall T., Scordo C., PMI-Acp Exam Prep Questions, Answers \& Explanations, ISBN 9780989470308, 442 pg., 2013.

[6] Ewusi-Mensah, Kweku. Software Development Failures. Cambridge, MA: MIT Press, 2003.

[7] Jones, Capers, Software Project Management Practices: Failure Versus Success, CrossTalk: The Journal of Defense Software Engineering, 2004

[8] Jones, Capers, Patterns of Software Systems Failure and Success. Boston, MA: International Thompson Computer Press, 1995.

[9] Eric T.G. Wang, Pei-Hung Ju, James J. Jiang, Gary Klein, The effects of change control and management review on software flexibility and project performance, Information \& Management, Volume 45, Issue 7, 2008, Pages 438-443, ISSN 0378-7206.

[10] Khan, Asadullah. "Project scope management." Cost engineering 48, 2006, 12-16.

[11] Henry A. Hornstein, The integration of project management and organizational change management is now a necessity, International Journal of Project Management, Volume 33, Issue 2, 2015, Pages 291298, ISSN 0263-7863.

[12] Vladimir Voropajev, Change management-A key integrative function of PM in transition economies, International Journal of Project Management, Volume 16, Issue 1, 1998, Pages 15-19, ISSN 02637863. 